\title{
Aquaporins in human platelets: intracellular localization and possible role in granule and lysosome secretion
}

\author{
Tomasz Misztal1', Tomasz Rusak1, Justyna Brańska-Januszewska², Marta Gąsowska1, \\ Beata Szynaka³, Agata Gołaszewska1, Marta Bruczko4 and Marian Tomasiak ${ }^{\bowtie}$
}

1Department of Physical Chemistry, Medical University of Bialystok, Bialystok, Poland; 2Department of Biology, Medical University of Bialystok, Bialystok, Poland; ${ }^{3}$ Department of Histology and Embryology, Medical University of Bialystok, Bialystok, Poland; ${ }^{4}$ Department of Medical Biochemistry, Medical University of Bialystok, Bialystok, Poland

This study was undertaken to establish the presence and the role of aquaporins (AQPs) in human platelets. Immunodetection with polyclonal antibodies and fluorescent microscopy suggest the presence of AQP isoforms - 0-7 and 9-12 - localized (in resting platelets) in the plasma membrane and in the dense and alpha granules. In thrombin- or monensin-treated platelets, the granules' AQPs become visible in the whole cell body, indicating the granules' swelling. In our studies on the role of AQPs in platelet responses we used tetrachloroauric acid $(\mathrm{HAuCl})$, a classical water channel blocker. We found that $10-100 \mu \mathrm{M}$ of $\mathrm{Au}(\mathrm{III})$ inhibited the hypotonicity-, monensin (simulating the action of $\mathrm{Na}^{+} / \mathrm{H}^{+}$exchanger)-, and collagen-evoked platelet swelling and reduced tritiated water uptake by platelets treated by collagen or monensin, indicating its ability to block water channels in these cells. $\mathrm{HAuCl}_{4}$, at the concentrations reducing water influx, did not induce cell lysis, alter the plasma membrane shape or the -SH group content. The inhibitor also failed to affect $\mathrm{Na}^{+}$and $\mathrm{Cl}^{-}$-related osmotic gradient formation and protein kinase $D_{2}$ phosphorylation. In platelets activated by threshold concentrations of collagen, the thrombin receptor activating peptide, ADP, calcium ionophore A23187, phorbol ester and arachidonic acid, $\mathrm{HAuCl}_{4}(100 \mu \mathrm{M})$ completely inhibited secretion of ATP from dense granules but failed to reduce platelet aggregation. In collagen-stimulated platelets, $\mathrm{HAuCl}_{4}(10-100 \mu \mathrm{M})$ reduced secretion from dense and alpha granules, as well as lysosomes, in a dose-dependent manner. We conclude that human platelets possess numerous AQPs subtypes localized in the plasma and granule membranes. AQP-mediated water fluxes may be crucial for platelet volume regulation as well as secretion from dense and alpha granules and lysosomes.

Key words: blood, platelets, aquaporins, aggregation, secretion, osmotic swelling

Received: 28 May, 2018; revised: 20 August, 2018; accepted: 07 September, 2018; available on-line: 22 November, 2018

e-mail: mtomask@umb.edu.pl

Abbreviations: $\mathrm{AF}$, Alexa Fluor; $\mathrm{AQP}(\mathrm{s})$, aquaporins(s); $\mathrm{BCECF}$ 2,7'-Bis-(2-Carboxyethyl)-5-(and-6)-Carboxyfluorescein; FITC, fluorescein isothiocyanate; MPV, mean platelet volume; MQAE, (N(Ethoxycarbonylmethyl)-6-methoxyquinolinium bromide); NHE, $\mathrm{Na}^{+} / \mathrm{H}^{+}$exchanger; NPA, asparagine-proline-alanine motif; OCS, open canalicular system; PBS, phosphate buffered saline; PE, phycoerythrin; PFA, paraformaldehyde; PF4, platelet factor 4; PKC, protein kinase $C_{;}$PKD $D_{2}$ protein kinase $D_{2}$; PMA, phorbol 12-myristate 13-acetate; PO, propylene oxide; PRP, platelet rich plasma; RIPA, radioimmunoprecipitation assay; SNARE, Soluble $\mathrm{N}$-ethylmaleimidesensitive factor Attachment protein Receptor; TEM, transmission electron microscopy; TRAP, thrombin receptor activating peptide; 5-HT, 5-hydroxytryptamine.

\section{INTRODUCTION}

Aquaporin water channels (AQPs), represent a large family of evolutionarily conserved, integral membrane proteins that mediate rapid and selective transport of water and small uncharged solutes (for example, glycerol) across cell and organelle membranes in response to osmotic gradients generated by ion exchangers and transporters (for instance, the $\mathrm{Na}^{+} / \mathrm{H}^{+}$exchanger, NHE) (Agre et al., 2002; Kato et al., 2006; Hub \& de Groot, 2008; Carbrey \& Agre, 2009; Verkman, 2012).

All AQP units can be described as homotetramers forming four channels within the membrane, resembling an hourglass-like structure, and acting as independent water pores (Sui et al., 2001; Walz et al., 2009; Khalili-Araghi et al., 2009). Monomers contain six transmembrane domains and five interhelical loops (designated A-E). Two of these loops (B and E), containing a highly conserved short hydrophobic region with a typical asparagine-proline-alanine motif (NPA box), form the extracellular and cytoplasmic vestibules of the aquaporin channel. The vestibules are connected by a narrow $(2.8 \AA$ in diameter for AQP1) constriction region (a pore) allowing a single-file water transport (Sui et al., 2001; Verkman, 2012).

To date, 13 members of the AQP family (designated AQP0-AQP12) have been described in various mammalian tissues (Agre et al., 2002; Ishibashi et al., 2011; Benga, 2012).

AQPs are sub-divided into three subfamilies depending on their genomic structure and selectivity: (1) waterspecific "classical" AQPs (2) aquaglyceroporins, and (3) superaquaporins (S-aquaporins). The aquaglyceroporins have a less constricted pore that allows them to be able to transport larger molecules, besides water, such as glycerol (Hub \& de Groot, 2008; Benga, 2012). S-aquaporins are highly deviated from previously known AQPs and have been found exclusively inside the cell, e.g. in the secretory granules (Ishibashi, 2006; Ishibashi et al., 2014).

Mammalian AQPs are expressed in various epithelia and endothelia, involved in fluid transport, as well as in a variety of cell types including erythrocytes, leukocytes, adipocytes, keratinocytes, astrocytes, and skeletal muscle cells (Schwab et al., 2012; Verkman et al., 2014).

Initially, it was thought that the major physiological role of AQPs in humans is restricted to transepithelial and transendothelial water movement, and the adaptation of cells to changes in osmotic pressure (Agre et al., 2002; Verkman, 2014). More recently, it has been discovered that AQPs constitute important components of the cellular migration machinery, where formation of filopodia 
and lamellipodia play a pivotal role (Saadoun et al., 2005; Papadopoulos et al., 2008; Verkman, 2014).

AQPs have been also proposed to be involved in water uptake by secretory vesicles of the exocrine pancreas cells (Cho et al., 2002; Sugiya \& Matsuki; 2006) and in the swelling of synaptic vesicles isolated from rat brains (Kelly et al., 2004; Jeremic et al., 2005). Secretory granule swelling is believed to be a necessary step in the release of their content (exocytosis) (Sugiya et al., 2008).

The role of AQPs in the physiology of human platelets is not completely understood. A study performed on platelets from three children with a mutation of the AQP7 gene indicated that human platelets possess AQP7 and that this AQP isoform may be important for platelet morphology, aggregation (adrenaline-induced), and secretion (Goubau et al., 2013). A more recent study also revealed presence of AQP1 in human platelets (Agbani et al., 2018). Using AQP1-null mice it was shown that this AQP isoform is crucial for the platelet procoagulant response. However, deletion of AQP1 had minimal effects on collagen-induced platelet secretion and aggregation. Yet, the presence of other AQPs and their relevance in platelet physiology is still not completely known.

Consequently, in this study we systematically examined, for the first time, the expression and localization of AQPs in human platelets and investigated their role in the platelet physiology.

\section{MATERIALS AND METHODS}

Materials. Rabbit polyclonal anti-human AQP0 (sc99059), APQ1 (sc-20810), AQP2 (sc-28629), AQP3 (sc20811), AQP4 (sc-20812), AQP5 (sc-28628), AQP6 (sc28627), AQP7 (sc-28625), AQP8 (sc-28624) and AQP9 (sc-28623) antibodies, normal rabbit polyclonal IgG (isotype control), horseradish peroxidase (HRP)-conjugated goat anti-rabbit, and HRP-conjugated goat anti-mouse antibodies were purchased from Santa Cruz Biotechnology. Rabbit polyclonal anti-human AQP11 antibody (PA5-25704), Alexa Fluor 488-conjugated and Alexa Fluor 568-conjugated goat anti-rabbit antibodies, N-(Ethoxycarbonylmethyl)-6-methoxyquinolinium bromide (MQAE) and enhanced luminescence Super Signal West Pico Substrate were from Thermo Fisher Scientific (Life Technologies). Rabbit polyclonal anti-human AQP10 (SAB4300715) and AQP12 (SAB4300758) antibodies, mouse anti-phosphoserine antibody ( $\mathrm{p}$-Ser), mepacrine, monensin, tetrachloroauric acid tetradydrate $\left(\mathrm{HAuCl}_{4}\right.$ $\times 4 \mathrm{H}_{2} \mathrm{O}$, here referred to as $\mathrm{Au}$ (III)), [ $\left.{ }^{3} \mathrm{H}\right] 5$-hydroxytryptamine (5-HT, serotonin) creatinine sulphate, tritiated water $\left({ }^{3} \mathrm{H}_{2} \mathrm{O}\right)$, thrombin receptor activating peptide (TRAP6), epinephrine (adrenaline) bitartate salt, DTNB (5,5'-dithiobis-(2-nitrobenzoic acid)), protease and phosphatase inhibitor cocktails were purchased from Sigma. Arachidonic acid, Chrono-Par collagen suspension (for simultaneous measurement of aggregation and ATP release), and luciferin-luciferase mix (Chrono-Lume) were from Chrono-Log Corporation. PE-conjugated mouse anti-human CD41a antibody, and FITC-conjugated mouse anti-human CD62P (P-selectin) antibody were purchased from Becton Dickinson. BCECF-AM (2',7'-Bis-(2-Carboxyethyl)-5-(and-6)-Carboxyfluorescein, Acetoxymethyl Ester) was purchased from Fluka. Human platelet factor 4 (PF4) ELISA kit was purchased from Abcam. Plastic microchambers (Thistle Scientific, type $\mu$-slide $\mathrm{VI}^{0.4}$ ) were purchased from Ibidi. Tirofiban (Aggrastat) were from Merck Sharp \& Dohme Idea Inc. Other chemicals were purchased from Sigma. $\mathrm{HAuCl}_{4}$ tetrahydrate was dissolved in deionized water and stock solutions ( $1 \mathrm{M}$ conc.) were stored at $-80^{\circ} \mathrm{C}$. Working solutions were prepared by making stock solution dilutions with sterile saline and kept at $-20^{\circ} \mathrm{C}$ for no longer than three weeks. Attention was taken to not exceed $0.25 \%(\mathrm{v} / \mathrm{v})$ of $\mathrm{HAuCl}_{4}$ solution in a sample (final concentration). Such additions did not evoke any noticeable changes in the samples' $\mathrm{pH}$.

Blood collection and platelet preparation. Blood was collected from healthy volunteers into $10 \mathrm{ml}$ polypropylene tubes containing $1 \mathrm{ml}$ of $130 \mathrm{mM}$ trisodium citrate. All procedures were conducted in accordance with the Declaration of Helsinki and the study was approved by the local Ethics Committee on human research. Platelet-rich plasma (PRP) was obtained by centrifugation of whole blood at $200 \times g$ for $20 \mathrm{~min}$. Washed platelets were prepared as described previously (Misztal et al., 2015). Gel-filtered platelets were prepared using a Sepharose $2 \mathrm{~B}$ gel filtration method. Platelet preparations were standardized to $2 \times 10^{8}$ cells $/ \mathrm{ml}$ with the TyrodeHepes buffer.

Fluorescent and confocal cell imaging. Confocal images were acquired using a Nikon Digital Eclipse C1Plus Modular Confocal System attached to an inverted fluorescence microscope - Nikon Eclipse Ti. The system is equipped with DS-Fi1 digital microscope camera (5-megapixel CCD that captures at a high resolution of $2560 \times 1920$ pixels) and the following laser lines: a violet diode laser (405 nm), an argon ion laser (488 nm), and a $\mathrm{HeNe}$ laser (543 nm). Images were captured with EZ-C1 software using an oil immersion Plan Apochromat objective lens $(60 \times / 1.4$ or $100 \times / 1.4)$.

Immunodetection and localization of AQP isoforms. Gel-filtered platelets were lysed by the addition of an equal volume of ice-cold radioimmunoprecipitation assay (RIPA) buffer supplemented with protease inhibitors cocktail. Lysates were analyzed towards AQP presence by Western Blotting with a chemiluminescent detection system. Lysates $(10 \mu \mathrm{g}$ of protein) of gel-filtered platelets were separated by SDS-PAGE under reducing conditions, followed by transfer onto a nitrocellulose membrane, blocking (with 5\% fat-free milk) and overnight incubation (at $4^{\circ} \mathrm{C}$ ) with primary antibody $(1: 1000$ dilution). After washing, blots were incubated for 1 hour at room temperature (RT) with the horseradish peroxidase (HRP)-conjugated secondary antibody (1:10000 dilution). Immunoreactive signals were measured by using an enhanced chemiluminescence reagent. Some adjustments in brightness were made (the same for each lane). Monomer subunits of AQPs are expected to run at 28-37 kDa; higher molecular-weight bands are likely to be stable multimers or highly glycosylated AQPs forms. Data are from four independent experiments, each performed on a separate platelet preparation. To check intraplatelet sublocalization of AQPs, aliquots of nonstimulated platelets were fixed by using an equal volume of $4 \%$ paraformaldehyde (PFA) in phosphate-buffered saline (PBS) for $30 \mathrm{~min}$ at RT. Next, the platelets were pelleted $(2200 \times g, 2 \mathrm{~min})$ and resuspended in PBS containing 3\% bovine serum albumin (BSA), supplemented (or not) with saponin $(0.04 \%$ final conc.) followed by incubation for $30 \mathrm{~min}$ at RT. After that, the platelets were pelleted again and resuspended in the same buffers as mentioned above, followed by the addition of an appropriate anti-AQP (0-12) antibody (one type of antibody per one sample, 1:500 dilution) and overnight incubation at $4^{\circ} \mathrm{C}$ with gentle agitation. After 3 washes, the samples were supplemented with a secondary antibody conjugated with Alexa Fluor 488 (1:250 dilution) and incubated 
for $1 \mathrm{~h}$ at RT. After 3 washing steps and final resuspension, aliquots $(25 \mu \mathrm{l})$ of platelets were transferred into microchamber slides (ibidi $\mu$-Slide $\mathrm{VI}^{0.4}$ ) and observed under a fluorescent microscope (Nikon ECLIPSE Ti/C1 Plus, $\times 100 / 1.4$ oil immersion objective) at the same gain value. In some experiments, the platelets were activated by thrombin or exposed to monensin before fixation in PFA. To assess whether AQPs can be localized within the platelet secretory granules, we used two-color labeling - concomitant detection of AQPs using Alexa Fluor 568-conjugated secondary antibody (1:250 dilution), and dense or alpha granules detection using mepacrine (10 $\mu \mathrm{M}$ final conc.) or FITC-anti-P-selectin antibody (1:25 dilution), respectively. Orange to pastel yellow color indicates signal co-localization. Isotype control primary antibody (normal rabbit $\operatorname{IgG}$ ) was used to evaluate potential nonspecific bindings. No relevant fluorescence was found when samples were incubated with only secondary antibodies.

Aggregation. Platelet aggregation was followed turbidimetricaly (in PRP) (Born \& Cross, 1963) or electronically (in whole blood) (Mackie et al., 1984) by using the Chrono-Log 700 lumiaggregometer (Chrono-Log Corp.)

Simultaneous measurement of platelet aggregation and ATP secretion. ATP release was monitored simultaneously with optical aggregation by using the Chrono-Log 700 lumiaggregometer. All procedures were conducted in accordance with the Chrono-Log Diagnostic Protocol.

Secretion. Serotonin (5-HT) secretion was studied by the isotopic method as described in (Tomasiak et al., 2004). Platelet factor 4 (PF4) release was measured by ELISA. P-selectin exposure on the surface of activated platelets was evaluated by using flow cytometry and by fluorescent microscopy. Hexosoaminidase release from lysosomes was assessed colorimetrically as described in (Nakagawa et al., 1978).

Measurement of rapid changes in the platelet volume. Changes in the platelet volume were followed spectrophotometrically by recording the absorbance at $680 \mathrm{~nm}$ in diluted cell suspensions, essentially as described in (Rosskopf et al., 1991). A drop in the absorbance reflects a rise in the cell volume. The changes in absorbance were measured at $37^{\circ} \mathrm{C}$ in plastic cuvettes (light path $10 \mathrm{~mm}$ ) without stirring. Changes in the platelet volume were evoked either by hypotonicity or by monensin. Aliquots of standardized PRP (140 $\mu \mathrm{l})$ supplemented with $\mathrm{HAuCl}_{4}(0-100 \mu \mathrm{M})$ were incubated for $2 \mathrm{~min}$ at $37^{\circ} \mathrm{C}$ in the cuvette of the instrument, then $860 \mu \mathrm{l}$ of an isotonic Tyrode-Hepes buffer ( $\mathrm{pH}$ 7.4), supplemented or not supplemented with monensin $(30$ $\mu \mathrm{M}$ final conc.), or a hypotonic Tyrode-Hepes buffer (final osmolality of $200 \mathrm{mOsm}$ ), all pre-warmed to $37^{\circ} \mathrm{C}$, were added. To ensure rapid mixing, the buffer was added via injector equipped with a silicone tube inserted into the cuvette. The changes in absorbance were recorded for $10 \mathrm{~s}$ at $0.1 \mathrm{~s}$ intervals using a spectrophotometer (Hitachi F-2900, Hitachi Corp., Japan) connected to a personal computer.

Measurement of mean platelet volume. Aliquots of standardized PRP $\left(2 \times 10^{8}\right.$ cells $\left./ \mathrm{ml}\right)$ supplemented with tirofiban $(250 \mathrm{ng} / \mathrm{ml})$, to prevent platelet aggregation, were incubated for $2 \mathrm{~min}$ at $37^{\circ} \mathrm{C}$ with or without $\mathrm{HAuCl}_{4}(10-100 \mu \mathrm{M})$. Next, collagen $(15 \mu \mathrm{g} / \mathrm{ml})$ or monensin $(30 \mu \mathrm{M})$ was added. After 5 min of incubation, platelets were fixed with paraformaldehyde $(2 \%$ final conc.) and their mean volume (MPV) was measured by using a hematologic analyzer (Coulter Electronic $\mathrm{GmbH})$.
Measurement of water uptake. Aliquots $(1 \mathrm{ml})$ of washed platelets $\left(2 \times 10^{8}\right.$ cells $\left./ \mathrm{ml}\right)$, supplemented with tirofiban $(250 \mathrm{ng} / \mathrm{ml})$, were incubated with stirring for $2 \mathrm{~min}$ at $37^{\circ} \mathrm{C}$ with $(10-100 \mu \mathrm{M})$ or without (control) $\mathrm{HAuCl}_{4}$. Afterwards, $7 \mu \mathrm{l}$ of tritiated water $(5 \mathrm{mCi}-185$ $\mathrm{MBq} / \mathrm{ml}$ ) were added and after $30 \mathrm{~s}$ of stirring, the platelet suspensions were supplemented with collagen $(15 \mu \mathrm{g} /$ $\mathrm{ml})$ or monensin $(30 \mu \mathrm{M})$. Prior to the addition of stimuli (time zero) and 2 minutes after the addition (uptake), aliquots $(0.4 \mathrm{ml})$ of the incubated mixture were aspirated for filtration. Filtration was performed under the pressure of $10 \mathrm{kPa}$ on Whatman GF/C filters (diameter 25 $\mathrm{mm}$ ). The filtered sample was immediately washed with $4 \times 5 \mathrm{ml}$ of ice-cold solution containing $0.15 \mathrm{M} \mathrm{NaCl}, 1$ $\mathrm{mM}$ EDTA and $5 \mathrm{mM}$ Hepes, $\mathrm{pH} \mathrm{7.4}$. After that, platelets remained on the filters were lysed with Soluene-350. The tritiated water, which remained inside platelets held on the filters, was measured in the scintillation counter (Ballad-1209, LKB) and expressed as disintegrations per minute $(\mathrm{dpm})$. Data are mean values $( \pm$ S.D.) of three independent experiments.

Platelet viability and thiol group determination. Viability of platelets exposed to $\mathrm{HAuCl}_{4}$ was evaluated by using the Trypan Blue uptake method (Strober, 2015) and by spectrophotometric measurement of the lactate dehydrogenase activity (eventually leaked from damaged platelets) in the fluid left after platelet removal, (Gutmann \& Wahlefeld, 1985). Thiol content in the washed platelets exposed to $\mathrm{HAuCl}_{4}$ was measured by using the Ellman reaction. Sulfhydryl group levels were calculated by using the molar absorption coefficient for DTNB (5,5'-dithiobis-(2-nitrobenzoic acid)) at $37^{\circ} \mathrm{C}$ (DTNB $\varepsilon_{412}=13800 \mathrm{M}^{-1} \mathrm{~cm}^{-1}$ ) (Eyaer et al., 2003).

Determination of platelet $\mathbf{P K D}_{2}$ serine residue phosphorylation. Phosphorylation of serine residues in $115 \mathrm{kDa}$ protein (reference mass of $\mathrm{PKD}_{2}$; Konopatskaya et al., 2011) in platelets was estimated by Western Blotting with a chemiluminescent detection system.

Measurements of cytosolic $\mathrm{Cl}^{-}$, and NHE activity in platelets. $\mathrm{Cl}^{-}$influx into collagen-activated platelets was monitored in MQAE-loaded platelets with monochromators set at $355 \mathrm{~nm}$ and $460 \mathrm{~nm}$ for excitation and emission wavelength, respectively (Koncz \& Daugirdas, 1994). The platelets were preloaded with $1 \mathrm{mM}$ MQAE (final conc.) for $45 \mathrm{~min}$ at ambient temperature under gentle rotation. Washed platelets were stimulated in a thermostated $\left(37^{\circ} \mathrm{C}\right)$ fluorimeter cuvette with stirring $(800 \mathrm{rpm})$. Stimulators were added directly to the stirred platelet suspension through a port in a fluorimeter cover by using a microsyringe. For evaluation of NHE activity, we monitored changes in the cytosolic $\mathrm{pH}$ of $\mathrm{BCE}$ CF-loaded platelets exposed to thrombin (Siffert et al., 1989). The platelets were loaded with BCECF acetoxymethyl ester (10 $\mu \mathrm{M}$ final conc.) mixed with Pluronic $137\left(0.005 \%\right.$ final conc.) for $60 \mathrm{~min}$ at $37^{\circ} \mathrm{C}$. Monochromators were set at $495 \mathrm{~nm}$ for the excitation wavelength and at $520 \mathrm{~nm}$ for the emission wavelength. In-apparatus conditions were as above.

Transmission electron microscopy (TEM). Samples $(0.5 \mathrm{ml})$ of PRP were incubated (or not incubated) with $\mathrm{HAuCl}_{4}(100 \mu \mathrm{M})$ for $10 \mathrm{~min}$ at $37^{\circ} \mathrm{C}$ with stirring. Then, collagen was added $(15 \mu \mathrm{g} / \mathrm{ml})$ and the decrease in light transmittance (reflecting shape change) and the ATP release from dense granules (detected luminometrically) were both monitored under the control of a lumiaggregometer (Chrono-Log 7000). At the moment of substantial shape change and the beginning of dense granules' release ( $\sim 45 \mathrm{~s}$ after the addition of collagen), 3 volumes of the fixing solution (containing $2 \%$ paraform- 

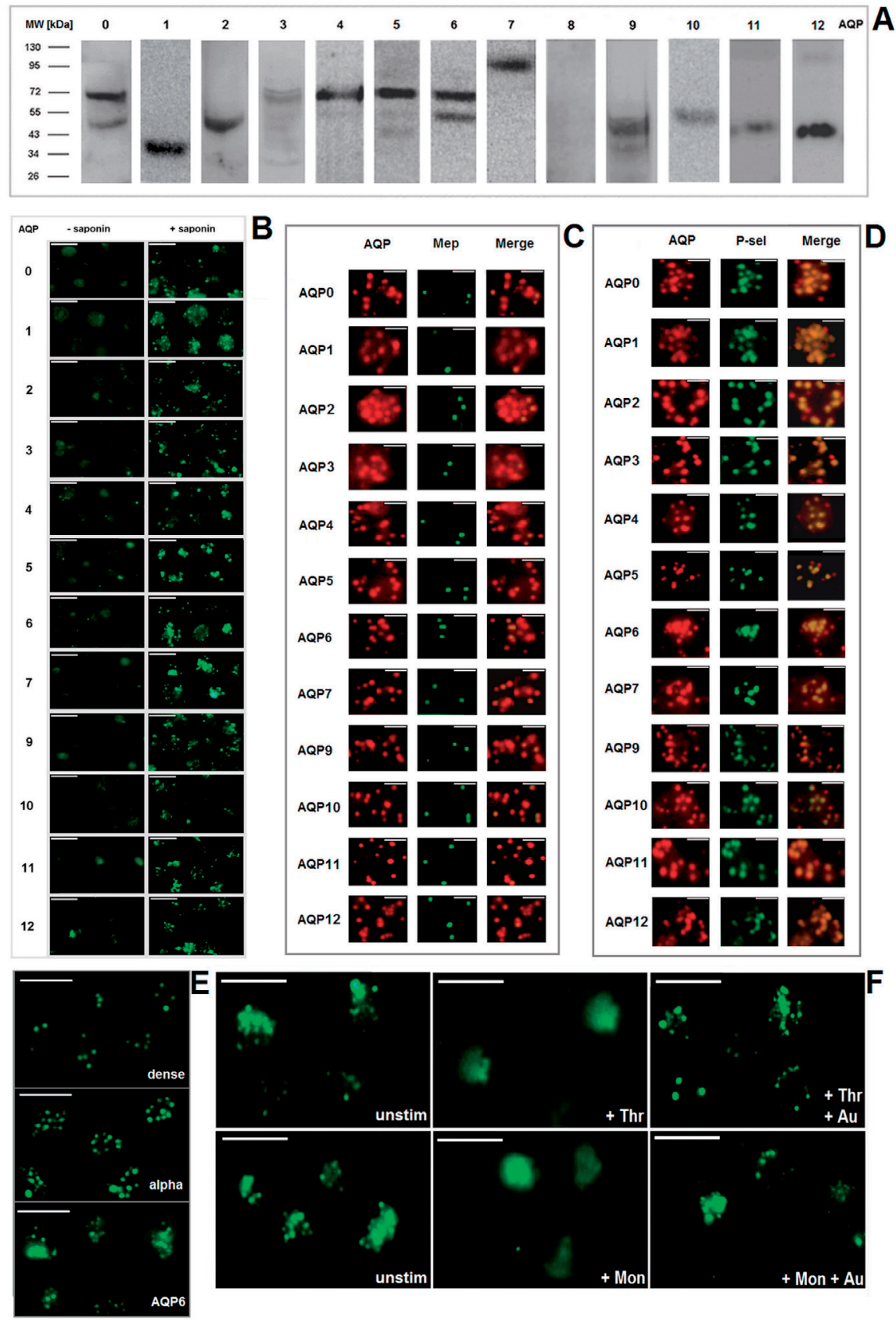

Figure 1. Identification and localization of aquaporins in human platelets.

(A) lysates $(10 \mu \mathrm{g}$ of protein) of gel-filtered platelets were separated by SDS-PAGE under reducing conditions, followed by Western Blotting towards AOP (isoforms from AOPO to AOP12) presence. Immunoreactive signals were measured by using an enhanced chemiluminescence reagent. Some adjustments in brightness were made (to the same for each lane). Monomer subunits of AQPs are expected to run at 28-37 kDa; higher molecular-weight bands are likely to be stable multimers or highly glycosylated AQPs forms. Data are from four independent experiments, each performed with a separate platelet preparation. (B-D) aliquots of non-stimulated platelets were fixed in 2\% (final conc.) PFA in PBS. After permeabilization (or not) with saponin, samples were mixed with an appropriate anti-AQP (0-12) antibody (one type of antibody per one sample) and incubated overnight at $4{ }^{\circ} \mathrm{C}$ with gentle agitation. After washing, samples were incubated with a secondary antibody conjugated with AF488 (green color in panel B). After washing and final resuspension, aliquots of platelets were transferred into microchamber slides and observed under fluorescent microscope at the same gain value. To assess whether AQPs can be localized within platelet secretory granules, we used two-color labeling - concomitant detection of AQPs using Alexa Fluor 568-conjugated secondary antibody (red color in panels C-D), and dense or alpha granule detection using mepacrine (green color in panel C) or FITC-anti-P-selectin antibody (green color in panel D), respectively. Orange to pastel yellow color indicates signal co-localization. At least 10 different areas from each sample were imaged. Representative fluorescent microscope images from one (out of four) experiment are presented. Isotype control primary antibody (normal rabbit lgG) was used to evaluate potential nonspecific bindings. No relevant fluorescence was found when samples were incubated only with the secondary antibodies. White bars represent $5 \mu \mathrm{m}$ (B) and $2 \mu \mathrm{m}(\mathrm{C}-\mathrm{D})$. (E) dense granules (dense), alpha granules (alpha) and AQPs were labeled and visualized as above. As an illustration of typical AQP localization inside platelets, the result from the AQP6 detection experiment is shown (with the notion that this localization pattern is representative in regard to other AQP isoforms found in platelets). Representative images from one (out of four) experiment are presented. White bar is $5 \mu \mathrm{m}$. (F) gel-filtered platelets were preincubated with or without $(+\mathrm{Au}) \mathrm{HAuCl}_{4}(100 \mu \mathrm{M}, 2 \mathrm{~min})$ and exposed to $5 \mathrm{nM}$ thrombin (+Thr) or $40 \mu \mathrm{M}$ monensin (+Mon) for $5 \mathrm{~min}$ at $37^{\circ} \mathrm{C}$, followed by fixation, saponization, overnight incubation with specific anti-AQP antibody, and visualized as described above. Control samples were without any (stimulator or inhibitor) additions (unstim). At least 10 different areas from each sample were imaged. Representative images from one (out of four) experiment involving AQP6 detection are presented. White bar is $5 \mu \mathrm{m}$. 

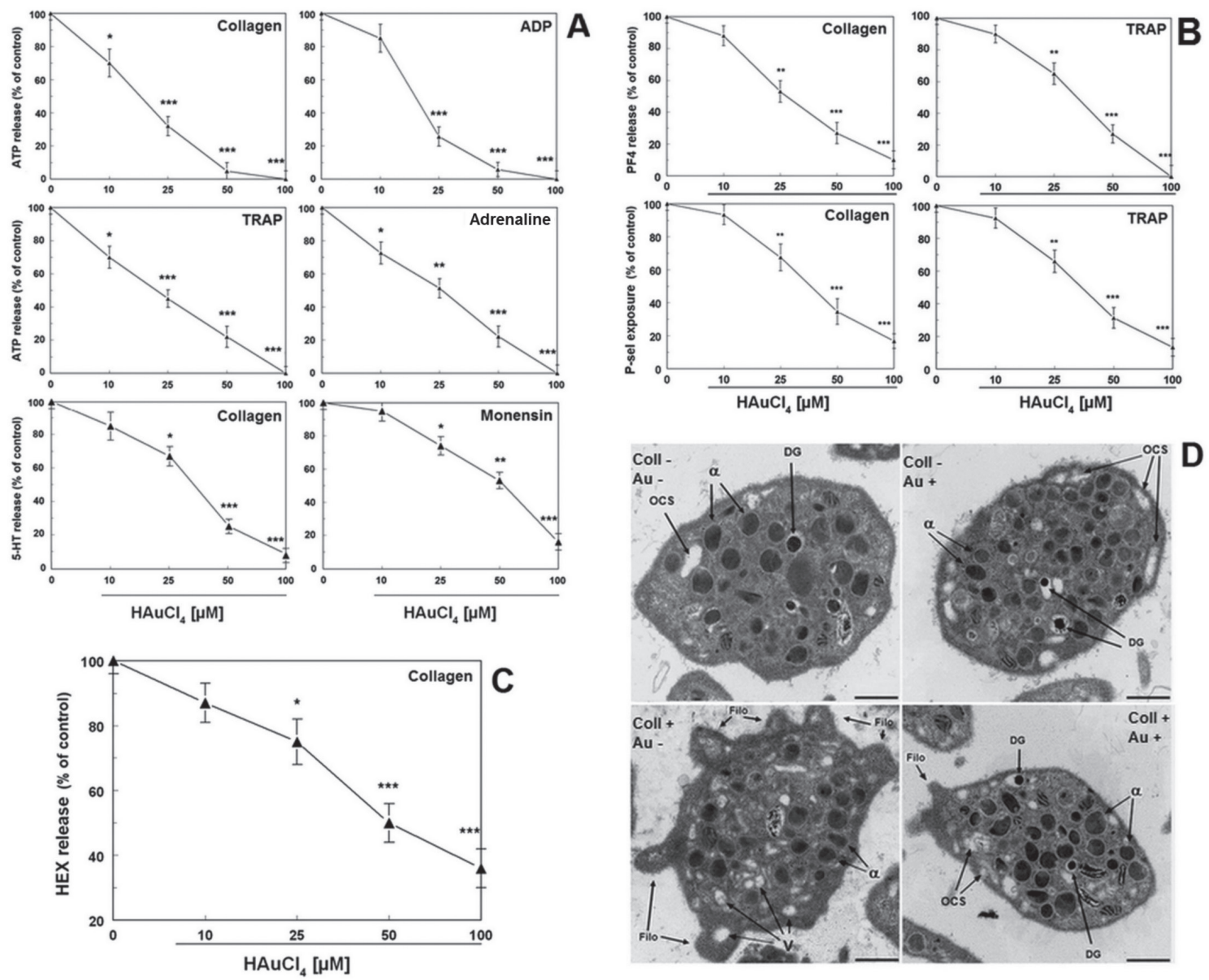

Figure 2. Inhibitory effect of $\mathrm{HAuCl}_{4}$ on platelet secretion.

(A) PRP samples were incubated for $2 \mathrm{~min}$ at $37^{\circ} \mathrm{C}$ with $\mathrm{HAuCl}_{4}(0-100 \mu \mathrm{M})$. Secretion was induced by the addition of collagen $(15 \mu \mathrm{g} /$ $\mathrm{ml})$; ADP $(10 \mu \mathrm{M})$; TRAP $(10 \mu \mathrm{M})$, or adrenaline $(10 \mu \mathrm{M})$. ATP released from platelets was monitored in a lumiaggregometer as described under Methods. The amount of ATP released within 4 min after addition of stimulus was measured. The maximum amount of ATP released from platelets untreated with $\mathrm{HAuCl}_{4}$ was taken as $100 \%$ (control). To determine serotonin secretion, aliquots of $\left.{ }^{3} \mathrm{H}\right] \mathrm{sero}-$ tonin-loaded platelets were incubated for $2 \mathrm{~min}$ at $37^{\circ} \mathrm{C}$ with $\mathrm{HAuCl}_{4}(0-100 \mu \mathrm{M})$. The amount of [3H]serotonin released within 4 min after the addition of collagen $(15 \mu \mathrm{g} / \mathrm{ml})$ or monensin $(30 \mu \mathrm{M})$ was estimated as described under Methods. The maximum amount of [ $\left.{ }^{3} \mathrm{H}\right]$ serotonin released from platelets untreated with $\mathrm{HAuCl}_{4}$ was taken as $100 \%$ (control). Data are presented as mean values ( \pm S.D.). All experiments were performed at least in quadruplicate using four different platelet preparations. (B) PRP samples were incubated for 2 min at $37^{\circ} \mathrm{C}$ with $\mathrm{HAuCl}(0-100 \mu \mathrm{M})$. Secretion was induced by the addition of collagen $(15 \mu \mathrm{g} / \mathrm{ml})$ or TRAP $(10 \mu \mathrm{M})$. The amount of PF4 and P-selectin released from platelets within 10 min after the addition of stimulus was estimated by ELISA or flow cytometry, respectively. The maximum amount of PF4 and P-selectin released from activated platelets untreated with $\mathrm{HAuCl}_{4}$ was taken as $100 \%$ (control). Data are mean values $( \pm$ S.D.) of four experiments, each performed with separate platelet preparation. (C) aliquots of washed platelets were incubated for $2 \mathrm{~min}$ at $37^{\circ} \mathrm{C}$ with $\mathrm{HAuCl}_{4}(0-100 \mu \mathrm{M})$. The activity of hexosoaminidase (HEX) released from platelets within 4 min after the addition of collagen $(15 \mu \mathrm{g} / \mathrm{ml})$ was estimated by using a colorimetric assay as described under Methods. The maximum activity of HEX released from platelets untreated with $\mathrm{HAuCl}_{4}$ was taken as $100 \%$ (control). Data are mean values $( \pm$ S.D.) of four experiments each performed (at least) in triplicate on separate platelet preparations. (D) platelets (in PRP) preincubated with (Au+, $100 \mu \mathrm{M})$ or without (Au-) $\mathrm{HAuCl}_{4}$ for $10 \mathrm{~min}$ at $37{ }^{\circ} \mathrm{C}$ with stirring, were activated (coll+) or not activated (coll-) for $45 \mathrm{sec}$ with collagen $(15 \mu \mathrm{g} / \mathrm{ml}$ ). Platelets were then fixed and visualized under a transmission electron microscope. "Filo" - filopodia, "DG" - dense granule, " $a$ " - alpha granule, "OCS" open canalicular system, and " $\mathrm{V}$ " - empty vesicles. Black bar is $500 \mathrm{~nm}$. Original magnification is $\times 20000$. ${ }^{*} P<0.05 ;{ }^{* *} P<0.01 ;{ }^{* * *} P<0.001$ vs control.

aldehyde and $2.5 \%$ glutaraldehyde in $0.1 \mathrm{M}$ cacodylate buffer) were added, mixed for $1 \mathrm{~min}$ and left for $1 \mathrm{~h}$ at $37^{\circ} \mathrm{C}$. Next, the platelets were sedimented $(2200 \times g, 2$ min) and the obtained pellet was flooded with $2 \%$ agarose in PBS. After agarose solidification, a few droplets of the fixing solution were laid on the top of each sample. After $24 \mathrm{~h}$ at $4^{\circ} \mathrm{C}$, the samples were washed several times with $0.1 \mathrm{M}$ cacodylate buffer followed by post-fixation in $1 \% \mathrm{OsO}_{4}$ After $1 \mathrm{~h}$, samples were washed with deionized water, followed by dehydration in a graded series of ethyl alcohol dilutions. The last step was performed in a mixture of $100 \%$ ethyl alcohol with propylene oxide (PO) $(1: 1 \mathrm{v} / \mathrm{v})$ followed by substitution with pure PO. After removing the PO, a series of mixtures containing PO and Epon (3:1, 1:1, and 1:3, respectively) were used for fixation followed by exposure of the samples to pure Epon for $2 \mathrm{~h}$. Next, the samples were transferred into polypropylene capsules and left for solidification at $60^{\circ} \mathrm{C}$ for at least $48 \mathrm{~h}$. The samples were then cut into $70 \mathrm{~nm}$-thin sections, placed on grids and post-stained using uranyl acetate, followed by post-staining with lead citrate. After a few washings with deionized water, the samples were examined with Zeiss Opton EM 900 transmission electron microscope.

Data analyses. Data reported in this paper are the mean $( \pm$ S.D.) of the number of determinations indicated 

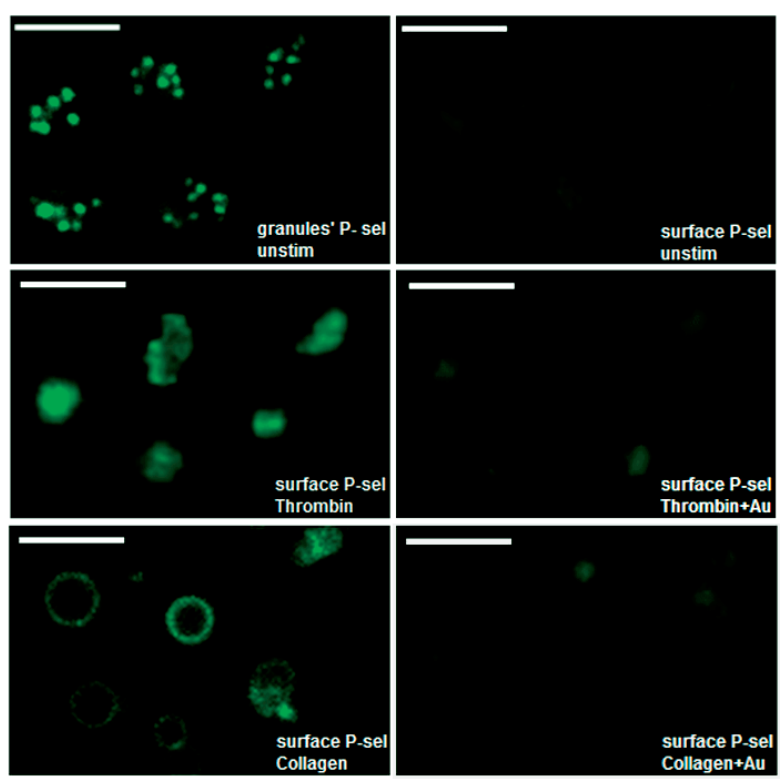

Figure 3. Inhibitory effect of $\mathrm{HAuCl}_{4}$ on P-selectin exposure on the surface of stimulated platelets.

Gel-filtered platelets were incubated (or not) for 2 min with HAu$\mathrm{Cl}_{4}(100 \mu \mathrm{M})$, followed by the addition of thrombin ( $4 \mathrm{nM}$, without stirring) or collagen $(15 \mu \mathrm{g} / \mathrm{ml}$, with initial $30 \mathrm{~s}$ stirring) for 10 min at $37^{\circ} \mathrm{C}$. Control samples (unstim) were without any additions. Next, samples were fixed ( $2 \%$ paraformaldehyde final conc.), supplemented with FITC-conjugated anti-P-selectin antibody $(1: 25)$ and incubated for another $20 \mathrm{~min}$ in darkness to stain the plasma membrane-associated P-selectin. To detect intracellular (alpha granules-associated) P-selectin, samples were supplemented with saponin $(0.04 \%$ final conc.) for 20 min prior to the addition of antibody. After 3 washes, samples were analyzed by using fluorescent microscope at the same gain setting for all samples. At least 10 different areas from each sample were imaged. Representative images from one experiment (out of three) are presented. White mark is $5 \mu \mathrm{m}$.

(n). Statistical analysis was performed by the Student's test (for paired data) and elaboration of experimental data by the use of Slide Write plus (Advanced Graphics Software, Inc. Carlsbad, CA, USA). In experiment where multiple comparisons were considered, analysis of variances (ANOVA) was used (Statistica, StatSoft, Tulsa, OK, USA). Differences were considered as significant at a $P$ value $<0.05$.

\section{RESULTS}

\section{Human platelets possess several AQP subtypes localized in the secretory granules and in the plasma membrane}

Figure 1A demonstrates the presence of 0-7 and 9-12 AQPs in human platelets. AQP3, AQP10 and AQP11 were poorly expressed, whereas AQP8 was untraceable. We found that in the platelets, the AQPs are localized within plasma membrane (Fig. 1B) and in granule-like structures (Fig. 1B-F). Two-color labeling showed that AQP-related immunoreactive signals co-localize with the dense (Fig. 1C) and alpha granules (Fig. 1D).

Given that secretory granules swell following platelet activation and eventually fuse with the plasma membrane/open canalicular system (OCS) (White, 1999), we further studied the subcellular localization of AQPs in platelets activated by thrombin or treated with monensin. Monensin (which simulates the action of the $\mathrm{Na}^{+} / \mathrm{H}^{+}$exchanger), was reported to induce swelling of secretory vesicles isolated from the chromaffin granules (Grinstein, 1982; Geisow \& Burgoyne, 1982) and to promote secretion of serotonin from platelets (Tomasiak et al., 2005). As can be seen in Fig. 1F - unlike in resting platelets, where AQPs are visible as distinctly separated spots (unswollen granules) - following stimulation by thrombin or pretreatment with monensin, AQP-related signals were almost randomly distributed in the whole cell body (swollen granules). This signal scattering was not observed following blockage of AQPs by $100 \mu \mathrm{M}$ concentration of $\mathrm{HAuCl}_{4}(\mathrm{Au}(\mathrm{III}))$ (Fig. 1F), a concentration that almost completely reduces secretion from the dense and alpha granules (Fig. 2A-B and D). A similar picture was observed in the case of P-selectin distribution in platelets activated by thrombin or collagen (Fig. 3). It is well accepted that in quiescent platelets, P-selectin is stored in the $\alpha$-granules and is exposed on the platelet surface following activation (Ollivier et al., 2014).

\section{$\mathrm{Au}(\mathrm{III})$ blocks water channels in human platelets}

To assess whether Au(III) blocks AQPs, we studied its impact on the rapid volume changes in platelets. As seen in Figs 4A-B, Au(III) $(10-200 \mu \mathrm{M})$ reduced the osmotic and monensin-produced swelling of platelets in a dose-dependent manner. In all cases, $100 \mu \mathrm{M}$ of $\mathrm{Au}(\mathrm{III})$ markedly inhibited the platelet swelling, indicating that this concentration of $\mathrm{Au}(\mathrm{III})$ is able to block the AQPs in platelets. Similar Au(III) concentrations reduced an increase in the mean platelet volume (Fig. 4C) and inhibited tritiated water uptake (Fig. 4D) in platelets stimulated by collagen or treated with monensin.

\section{$\mathrm{Au}$ (III) failed to affect ion fluxes necessary for osmotic gradient formation}

Since water influx through AQPs critically depends on osmotic gradient across the plasma membrane, we tested whether Au(III) affects the ion fluxes in platelets stimulated by thrombin or collagen. Au(III) $(100 \mu \mathrm{M})$ did not modulate the NHE activity (generating $\mathrm{Na}+$ influx) or a rise in cytosolic $\mathrm{Cl}^{-}$concentration following treatment with thrombin or collagen, respectively (Fig. 5A-B).

\section{Lack of cytotoxicity of $\mathrm{Au}$ (III) towards platelets at concentrations reducing rapid swelling}

$\mathrm{Au}(\mathrm{III})$ (up to $1 \mathrm{mM}$ ) did not disrupt the plasma membrane of platelets as judged by the trypan blue uptake and lactate dehydrogenase release tests (Fig. 6A-B). $\mathrm{Au}(\mathrm{III})$ (up to $100 \mu \mathrm{M}$ ) did not distinctly affect the content of $-\mathrm{SH}$ groups in the platelets (Fig. 6C). We also did not observe alterations within the platelet plasma membrane exposed to $\mathrm{Au}(\mathrm{III})(100 \mu \mathrm{M})$, as examined by TEM (Fig. 7).

\section{Blocking of AQPs results in strong inhibition of platelet secretion from the dense granules}

$\mathrm{Au}(\mathrm{III})(10-100 \mu \mathrm{M})$ reduced secretion of ATP in a dose-dependent manner from platelets activated by collagen, a thrombin receptor activating peptide (TRAP), adenosine diphosphate (ADP), and epinephrine (Fig. 2A). Blocking of AQPs by $100 \mu \mathrm{M}$ of $\mathrm{Au}(\mathrm{III})$ fully reduced the ATP release from the platelet dense granules stimulated by collagen, ADP, TRAP, adrenaline, arachidonic acid, calcium ionophore A23187, and phorbol 12-myristate 13-acetate (PMA) which was not associated with 

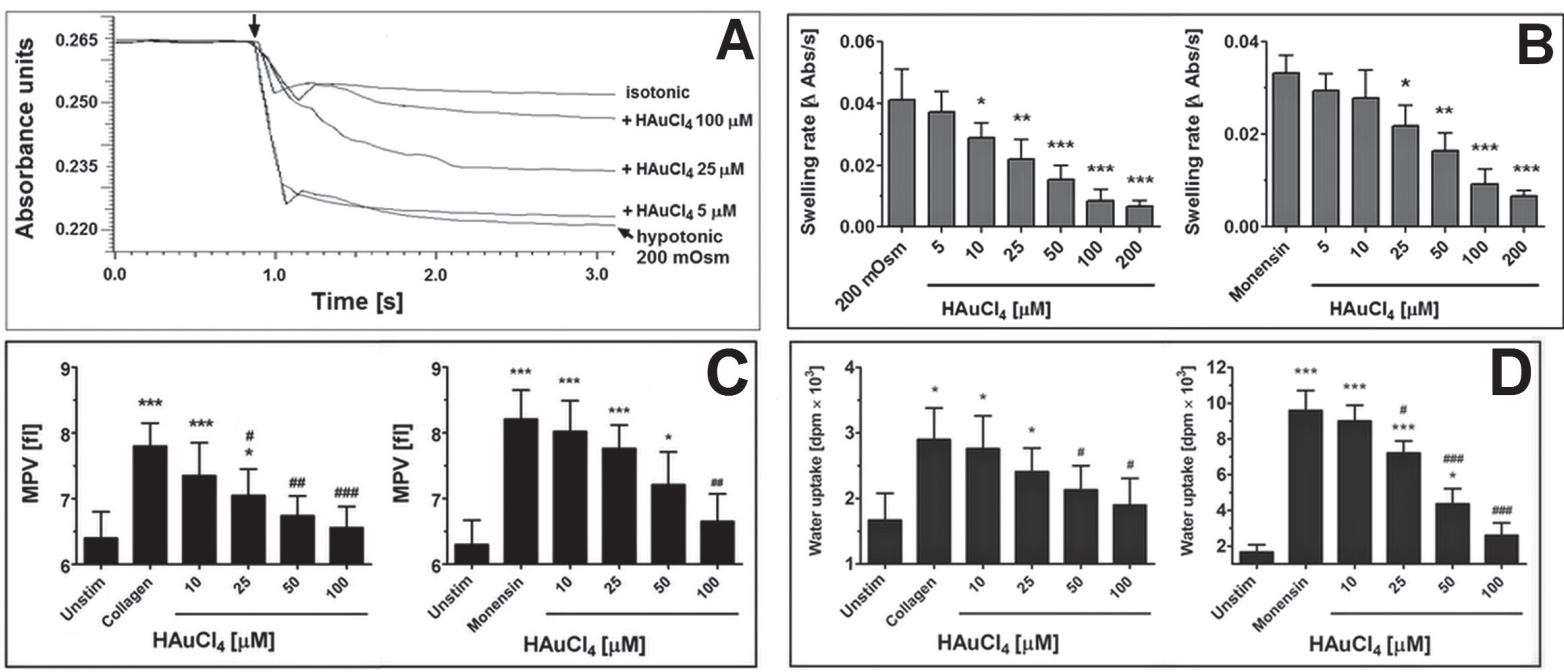

Figure 4. Impact of $\mathrm{HAuCl}_{4}$ on rapid platelet volume changes.

(A-B), PRP samples were preincubated with stirring for $2 \mathrm{~min}$ at $37^{\circ} \mathrm{C}$ with $\mathrm{HAuCl}_{4}$ added to the final concentrations as indicated. Experiments were started by the injection (arrow) of isotonic Tyrode-Hepes buffer, supplemented or not supplemented with monensin (30 $\mu \mathrm{M}$ final conc.), or low-osmolality Tyrode-Hepes buffer (200 mOsm final osmolality). Changes in volume (swelling) were followed spectrophotometrically (panel A). A drop in the absorbance reflects a rise in the cell volume. Representative traces and bars demonstrating swelling rate $(\Delta \mathrm{Abs} / \mathrm{s})$ are shown (panel B). Data from four independent experiments (mean values \pm S.D.), each in triplicate (at least), are presented. White bar is $5 \mu \mathrm{m}$. (C) platelets preincubated with or without $\mathrm{HAuCl}_{4}$, added to the final concentrations as indicated, were stimulated with collagen or monensin and after 5 min of incubation their mean volume (MPV) was measured. Control samples were without any additions (unstim). The data represent mean values $( \pm$ S.D.) of four independent experiments (each in triplicate). (D) washed platelets,

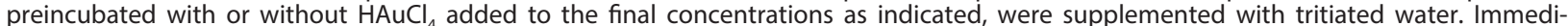
ately after that and 2 minutes after the addition of a stimulator (collagen or monensin), samples of incubated mixtures were aspirated for filtration. Control samples were without any additions (unstim). The radioactivity (dpm) of tritiated water that remained in platelets held on the filters was measured. Data are the mean values $( \pm$ S.D.) of three independent experiments (each in triplicate). In all panels: ${ }^{*} P<0.05 ;{ }^{* *} P<0.01 ;{ }^{* * *} P<0.001$ vs control; $\# P<0.05 ; \# \# P<0.01 ; \# \# \# P<0.001$ vs conditions with collagen.
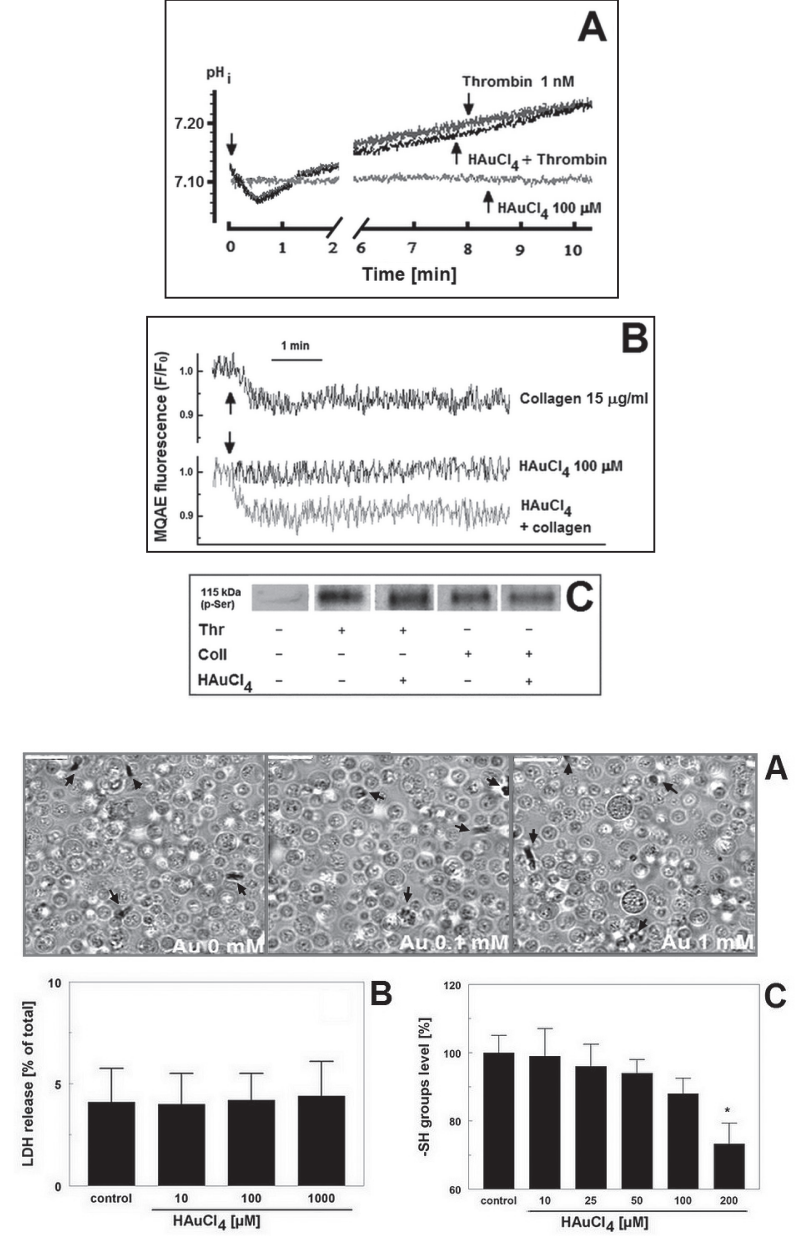

Figure 5. $\mathrm{HAuCl}_{4}$ failed to affect NHE activity, chloride ions influx, and $\mathrm{PKD}_{2}$ phosphorylation in stimulated platelets.

BCECF-loaded (for assessment of NHE activity via $\mathrm{pH}$ measurement, (panel A) or MQAE-loaded (for detection of $\mathrm{Cl}^{-}$ions influx, (panel B) washed platelets were preincubated for 2 min with or without $\mathrm{HAuCl}_{4}\left(0-100 \mu \mathrm{M}\right.$ f.c.) at $37^{\circ} \mathrm{C}$. After that, platelet suspensions were transferred into thermostated $\left(37^{\circ} \mathrm{C}\right)$ cuvette containing Tyrode buffer supplemented with $\mathrm{CaCl}_{2}$ (1 mM f.c.). Thrombin (1-4 nM f.c.) or collagen $(15 \mu \mathrm{g} / \mathrm{ml} \mathrm{f.c.)} \mathrm{was} \mathrm{added} \mathrm{to} \mathrm{the} \mathrm{stirred}$ suspension (pointed by the arrow on the left side of each image) after stabilization of basal fluorescent signal. Representative traces of changes in intracellular $\left[\mathrm{Cl}^{-}\right]$and $\mathrm{pH}$ value from one experiment (out of six, each in triplicate) are presented. (C), gel-filtered platelets $\left(2 \times 10^{8} / \mathrm{ml}\right)$ were incubated for 2 min with $\mathrm{HAuCl}_{4}(100 \mu \mathrm{M})$ followed by the addition of thrombin (Thr, $5 \mathrm{nM}$ ), without stirring, or collagen (Coll, $15 \mu \mathrm{g} / \mathrm{ml}$ ) with initial (30 s) stirring. After $5 \mathrm{~min}$ of exposure at $37^{\circ} \mathrm{C}$, platelets were lysed by the addition of ice cold RIPA buffer supplemented with phosphatase and protease inhibitor cocktail. Samples $(10 \mu \mathrm{g}$ of proteins) were analyzed to determine the level of phosphorylation of serine residues ( $p$-Ser) in $115 \mathrm{kDa}$ platelet protein (corresponding to protein kinase $D_{2}$ $\mathrm{PKD}_{2}$ ) by Western Blotting using primary anti-phosphoserine antibody $(1: 5000)$ and secondary HRP-conjugated antibody (1:20 000). Immunoreactive signals were visualized by using an enhanced chemilumienscence detection system. A representative result from one (out of three) experiment is presented.

Figure 6. Effect of $\mathrm{HAuCl}_{4}$ on platelet viability and free sulfhydryl groups content.

(A) samples of PRP were incubated for $60 \mathrm{~min}$ at $37^{\circ} \mathrm{C}$ with or without (control) $\mathrm{HAuCl}_{4}$ (up to $1 \mathrm{mM}$ ) followed by the addition of Trypan Blue in PBS (0.05\% final conc.). After 15 min of incubation at $37^{\circ} \mathrm{C}$, the samples were transferred into microchamber slides and observed under bright field microscopy. Dark blue color, associated with dye uptake (pointed by arrows), indicates plasma membrane damage. (B) samples of PRP were incubated for $60 \mathrm{~min}$ at $37^{\circ} \mathrm{C}$ with or without (control) $\mathrm{HAuCl}_{4}$ (up to $1 \mathrm{mM}$ ). Next, platelets were centrifuged and the lactate dehydrogenase activity in the supernatant was assessed by a spectrophotometric method. (C) samples of washed platelets were incubated for 20 min at $37^{\circ} \mathrm{C}$ with or without (control) $\mathrm{HAuCl}_{4}(10-200 \mu \mathrm{M})$. The content of thiol (-SH) groups in platelets was measured by using the DTNB assay. The total free-SH groups content in platelets was about $113.9 \pm 14$ nmoles $/ 2 \times 10^{8}$ cells. Data are mean values $( \pm$ S.D.) or representative spectra of three independent experiments (each in triplicate). ${ }^{*} P<0.05$. 


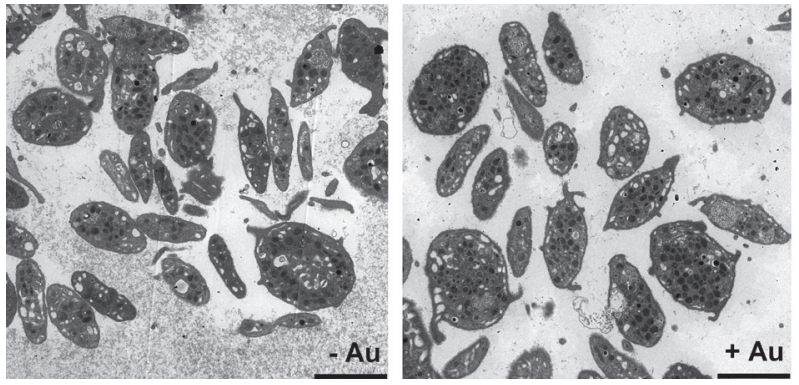

Figure 7. Lack of impact of $\mathrm{HAuCl}_{4}$ on platelet ultrastructure. Platelets (in PRP) were preincubated with $(\mathrm{Au}+, 100 \mu \mathrm{M})$ or without $(\mathrm{Au}-) \mathrm{HAuCl}_{4}$ for $10 \mathrm{~min}$ at $37^{\circ} \mathrm{C}$, followed by fixation in paraformaldehyde. Platelet ultrastructure was visualized under atransmission electron microscope. Black bar is $2500 \mathrm{~nm}$. Original magnification is $\times 5000$. Representative micrographs form one experiment (out of three) are presented. reduction in the platelet aggregatory response (Fig. 8). $\mathrm{Au}(\mathrm{III})(10-100 \mu \mathrm{M})$ inhibited collagen- or monensin-induced serotonin secretion from platelets in a dose-dependent fashion (Fig. 2A). TEM examination revealed that $\mathrm{Au}(\mathrm{III})(100 \mu \mathrm{M})$ reduced the emptying of dense granules in platelets stimulated by collagen (Fig. 2D).

Inhibition of APQs by $A u(I I I)$ results in reduction of secretion from the platelet a granules

$\mathrm{Au}(\mathrm{III})(10-100 \mu \mathrm{M})$ reduced the release of PF4 and P-selectin from collagen- or TRAP-stimulated platelets (Fig. 2B), in a dose-dependent manner.

\section{Blockage of AQPs by $\mathrm{Au}(\mathrm{III})$ distinctly reduces secretion from the platelet lysosomes}

$\mathrm{Au}(\mathrm{III})(10-100 \mu \mathrm{M})$ inhibited secretion of hexosaminidase from collagen-stimulated platelets in a dose-dependent manner (Fig. 2C).
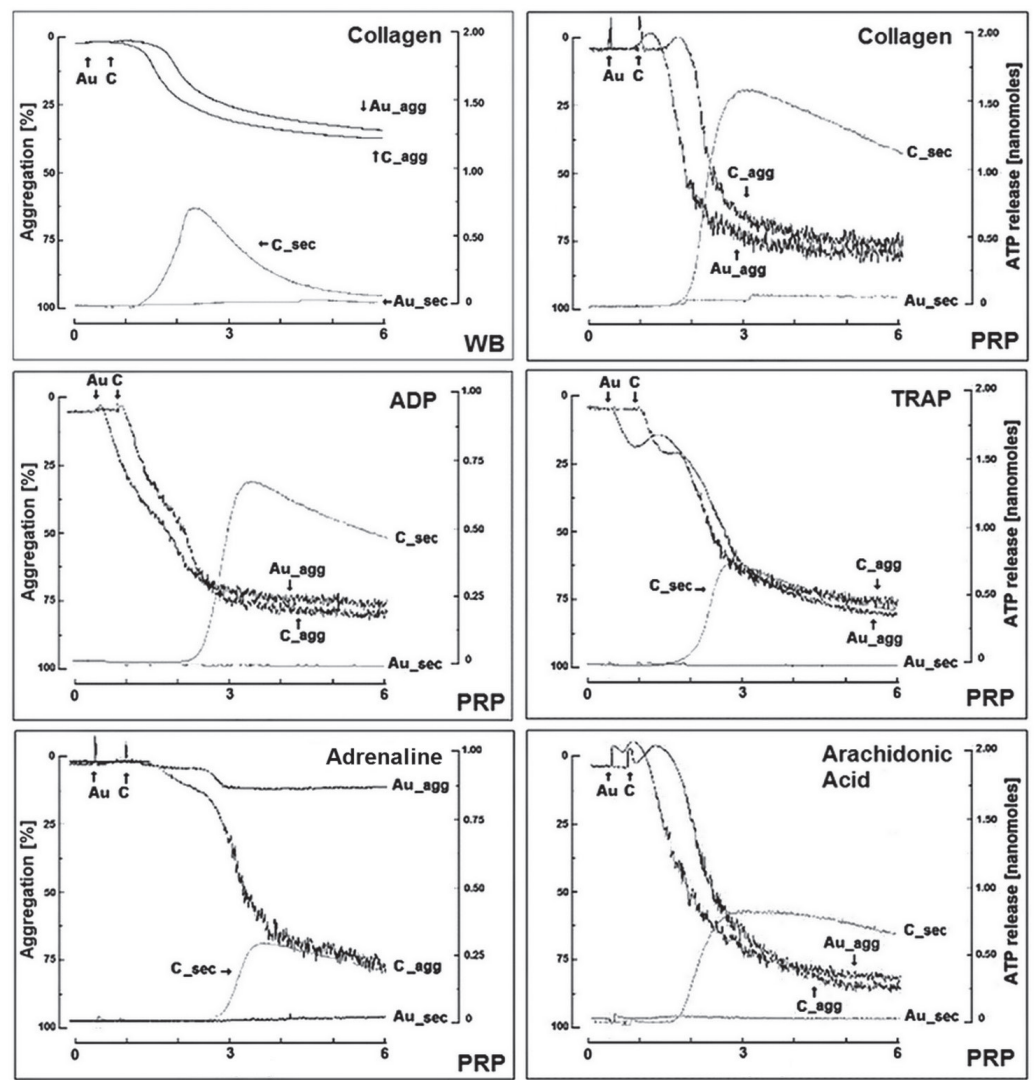
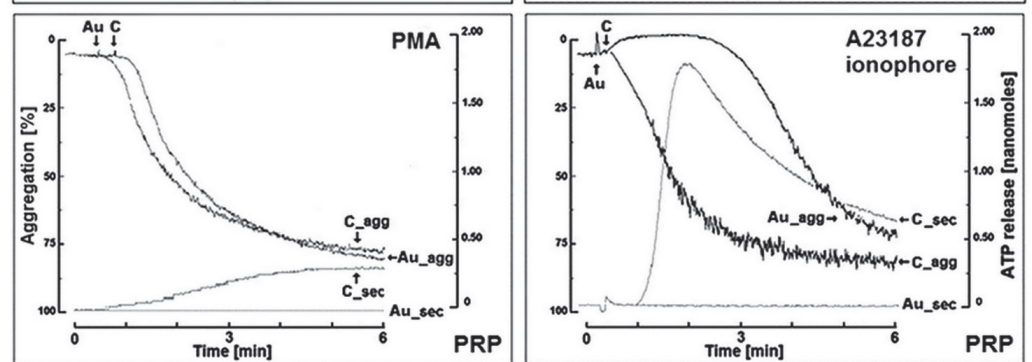

Figure 8. $\mathrm{HAuCl}_{4}$ differently reduced aggregation and dense granule secretion.

Samples of PRP or whole blood (WB) were incubated for $3 \mathrm{~min}$ at $37^{\circ} \mathrm{C}$, with or without (control, C) $100 \mu \mathrm{M}$ of $\mathrm{HAuCl}_{4}$ (Au). Aggregation (C_agg, Au_agg) and ATP secretion ( $C$ sec, Au sec) were initiated (arrows at the upper left corner of each panel) by the addition of collagen (Chrono-Par reagent, $2 \mu \mathrm{g} / \mathrm{ml})$, ADP $(10 \mu \mathrm{M})$, TRAP $(10 \mu \mathrm{M})$, adrenaline (10 $\mu \mathrm{M})$ or arachidonic acid $(1 \mathrm{mM})$. All concentrations are final concentrations in the samples. Electronic aggregation (WB panel) or optical aggregation (PRP panels) and ATP release were monitored simultaneously by using a lumiaggregometer as described under Methods. Representative traces from one experiment (out of 8 , each in triplicate) are presented.
$\mathrm{Au}(\mathrm{III})$ failed to affect agonistinduced protein kinase D2 phosphorylation

$\mathrm{Au}(\mathrm{III})$, at concentrations completely blocking dense granule secretion $(100 \mu \mathrm{M})$, did not affect phosphorylation of serine residues in the $115 \mathrm{kDa}$ protein (a marker of protein kinase $\mathrm{D}_{2},\left(\mathrm{PKD}_{2}\right)$ phosphorylation, Fig. 5C), a prerequisite for thrombin- or collagen-evoked dense granule secretion (Stafford et al., 2003).

\section{Minor role of AQPs in the platelet aggregation}

Blocking of AQPs by Au(III), up to $100 \mu \mathrm{M}$, failed to reduce the aggregation of platelets stimulated by the threshold concentrations of collagen, ADP, TRAP, arachidonic acid, or PMA (Fig. 8). Collageninduced aggregation was not sensitive to $\mathrm{Au}(\mathrm{III})$, irrespective of whether it was measured in the whole blood or in PRP. Aggregation induced by the A23187 ionophore was the only one that begun with a distinct delay. When aggregation was triggered by adrenaline, 100 $\mu \mathrm{M}$ of $\mathrm{Au}(\mathrm{III})$ strongly reduced the second wave of response.

\section{DISCUSSION}

The results presented here suggest that besides recently discovered AQP1 (Agbani et al., 2018) and AQP7 (Goubau et al., 2013), human platelets are likely to possess ten additional subtypes of AQP family members belonging to the subfamilies of classical aquaporins (AQPs 0-2 and AQPs 4-6), aquaglyceroporins (AQP3, AQP7, AQP9 and AQP10) and superaquaporins (AQP11 and 12) (Fig. 1A). 
In platelets, AQPs are localized in the plasma membrane and intracellularly, particularly in the dense and alpha granules (Fig. 1B-D). Interestingly, the platelet granules contain superaquaporins (AQP11 and 12) i.e. subtypes of AQPs family so far exclusively found inside the cells (10-12). Great diversity of AQPs, as well as their localization in the granules, indicate their importance for platelet function.

To study the role of AQPs in the platelet physiology, we employed 10-100 $\mu \mathrm{M}$ tetrachloroauric acid (here referred to as "Au(III)") as an inhibitor of water channels. $\mathrm{Au}(\mathrm{III})$ in the form of $\mathrm{HAuCl}_{4}$ is known to inhibit $\left(\mathrm{IC}_{50}=14 \mu \mathrm{M}\right) \mathrm{AQP1}$ in the murine and human erythrocytes (RBC) (Yang et al., 2006). Synthetized gold(III) complexes (like Auphen) have been reported to inhibit AQP3 and AQP7, expressed in human RBC (Martins et al., 2012) and in adipocytes (Madeira et al., 2014), respectively. Heavy-metal, sulfhydryl-reactive small molecules, such as $\mathrm{Hg}(\mathrm{II})$ and $\mathrm{Au}(\mathrm{III})$ (classical AQPs inhibitors), are currently the best established blockers of different subtypes of water channels (Esteva-Font et al., 2016). Inhibition of water channels by classical inhibitors (including $\mathrm{Au}^{3+}$ ) is thought to occur via interactions with the -SH group of the cysteine residues protruding into the water channel (Martins et al., 2012; Madeira et al., 2014; Estava-Font et al., 2016). Additionally, $\mathrm{Au}^{3+}$, with the ion diameter of $\sim 2.7 \AA$, matches the predicted AQP pore diameter of $2.8 \AA$ (Niemietz \& Tyerman, 2002). This combination of reactivity and size most likely constitutes the basis of the observed inhibitory effect. The disadvantage is that the mentioned ions block water channels at relatively high concentrations and may be toxic (especially $\mathrm{Hg}$ ) to living cells. Despite numerous efforts to identify novel non toxic small-molecule inhibitors, classical AQP inhibitors, especially $\mathrm{Au}(\mathrm{III})$ seem to be currently the best established water channel blockers (de Almeida et al., 2017; Esteva-Font et al., 2016).

The results presented here show that $\mathrm{Au}(\mathrm{III})$, at relatively low micromolar concentrations $(10-100 \mu \mathrm{M})$, inhibited hypoosmotically- or monensin-evoked (due to $\mathrm{Cl}^{-}$and $\mathrm{Na}^{+}$influx) rapid platelet swelling (Fig. 4B) - a phenomenon critically dependent on the AQPs action (Verkman, 2012). Since AQPs are likely to be involved in both of the above mentioned types of rapid swelling, this may indicate involvement of $\mathrm{Au}(\mathrm{III})$ in the platelet water channel blocking. The observation that Au(III) inhibits tritiated water uptake by platelets treated with collagen or monensin is consistent with this idea (Fig. 4D).

$\mathrm{Au}(\mathrm{III})$ compounds are much less toxic than commonly used $0.3 \mathrm{M}$ mercury chloride. Experiments with $\mathrm{NaAuCl}_{4}$ reveal its relatively low toxicity to mice (Suwalsky et al., 2004). However in the same study it was also suggested that $\mathrm{NaAuCl}_{4}$ (at $0.1-10 \mathrm{mM}$ concentrations) may affect morphology (shape) of red blood cells suspended in an artificial medium. Specifically, following one hour incubation with $0.1 \mathrm{mM} \mathrm{HAuCl}_{4}$, some red cells changed their normal discoid shape into stomatocytes (a cup-shaped form with evagination of one surface and a deep invagination of the opposite face). This was suggested to result from interaction of $\mathrm{Au}(\mathrm{III})$ with the phospholipids in the inner leaflet of the plasma membrane. However, it should be stressed that $\mathrm{Au}(\mathrm{III})$-related stomatocytosis of RBC was observed in washed cells suspended in buffered saline, i.e. in a highly non-physiological environment. In our experimental model we did not observe stomatocyte or echinocyte (RBC with many small thorny projections) formation following incubation of $\mathrm{RBC}$ suspended in plasma (i.e. under conditions much more relevant to the in vivo situation and similar to those used in our study) even following one hour of incubation of whole blood with up to $1 \mathrm{mM} \mathrm{HAuCl}_{4}$ (observations performed under an optical microscope, results not shown here). Under the same conditions, $\mathrm{HAuCl}_{4}$ did not induce RBC hemolysis (not shown). These observations make the direct effect of $\mathrm{Au}(\mathrm{III})$ on platelet membrane highly unlikely, at least under experimental conditions that we used here, i.e. short $(3-5 \mathrm{~min})$ exposure of platelets (suspended in the plasma or in the medium containing albumin) to $10-100 \mu \mathrm{M} \mathrm{HAuCl}$. This notion is further strengthened by the finding that exposure of platelets to $100 \mu \mathrm{M} \mathrm{Au}$ (III) for $10 \mathrm{~min}$ did not result in alterations in the platelet ultrastructure (including invagination in platelet plasma membrane) examined under transmission electron microscope (Fig. 7). Accordingly, by using the LDH and trypan blue tests we showed that following one hour incubation of platelets suspended in plasma with $1 \mathrm{mM} \mathrm{Au}(\mathrm{III})$, their plasma membrane remains intact (Fig. 6A-B).

To sum up, the substantial influence of $\mathrm{Au}$ (III) on platelet membrane is excluded, at least under the experimental conditions that we used for functional studies, i.e. short (3-5 $\mathrm{min})$ exposure of platelets to $10-100 \mu \mathrm{M}$ $\mathrm{Au}(\mathrm{III})$.

Studies performed with several synthetic gold (III) COordinated complexes displaying anti tumor activity reveal that their cytostatic activity can be associated with inhibition of thioredoxin reductase and impairment of mitochondria (Barnard \& Berners-Price, 2007; Taotao et al., 2015). Platelets contain a thioredoxin reductase and its inhibition was recently reported to result in attenuation of the platelet-mediated clot retraction (Metcalfe et al., 2016). These effects were proposed to result from interactions of $\mathrm{Au}(\mathrm{III})$ with intracellular $\mathrm{SH}$ groups (Metcalfe et al., 2016; Taotao et al., 2015). However, treatment of platelets with $100 \mu \mathrm{M}$ of $\mathrm{Au}(\mathrm{III})$ for $20 \mathrm{~min}$ did not result in a significant decrease in $\mathrm{SH}$ group content in the platelets (Fig. 6C). What is more, treatment of platelets with $100 \mu \mathrm{M}$ of $\mathrm{Au}(\mathrm{III})$ did not result in alteration of kinetics of clot retraction (results not shown). Since kinetics of clot retraction is critically dependent on energy production in the platelet mitochondria (Misztal et al., 2013; Misztal et al., 2014; Misztal et al., 2014), this means that $\mathrm{Au}(\mathrm{III})$ does not distinctly affect functionality of the platelet mitochondria. This makes the impact of $\mathrm{Au}(\mathrm{III})$ on platelet thioredoxin reductase and mitochondria unlikely, at least under the experimental conditions we used here.

The possibility that $\mathrm{Au}(\mathrm{III})$ affects ion fluxes (preceding generation of local osmotic disequilibrium (necessary for AQPs-mediated water influx) (Schwab et al., 2012) is also excluded since the concentrations of $\mathrm{Au}(\mathrm{III})$ inhibiting rapid platelet swelling (i.e. up to $100 \mu \mathrm{M}$ ) failed to reduce the influx of osmotically active $\mathrm{Cl}^{-}$and $\mathrm{Na}^{+}$into the cytosol of platelets activated by thrombin or collagen (Fig. 5A-B).

Combined, the findings of this study show that $\mathrm{HAuCl}_{4}$, at the concentrations of $10-100 \mu \mathrm{M}$, may serve as a potent and selective inhibitor of AQPs in platelets.

Results presented here show that AQPs are essential for platelet secretion from the dense granules, alpha granules, and from lysosomes. Blocking of AQPs reduced platelet secretion considerably (Fig. 2A-D, Fig. 3, Fig. 8). Notably, blocking of platelet AQPs by $100 \mu \mathrm{M}$ $\mathrm{HAuCl}_{4}$ resulted in complete inhibition of secretion from the dense granules (Fig. 2A and 8) induced by all principal physiological and pharmacological activators, including activator of the thrombin receptor. The question arises: how may AQPs contribute to platelet secretion? 
The current model of the platelet secretory process considers that a crucial step in exocytotic secretion is fusion of the membranes of secretory granules with the membranes of the open canalicular system (OCS)/plasma membrane (Lemons et al., 1997; Sudhof \& Rothman, 2009; Fang \& Lindau, 2014; Mellander et al., 2014). It is also recognized that in platelets, membrane fusion is mediated by the assembly of the SNARE (Soluble N-ethylmaleimide-sensitive factor Attachment protein REceptor) complex (Sudhof \& Rothman, 2009; Peng et al., 2013). However, the central role of SNARE proteins in platelet secretion is still not certain (Golembiewska \& Poole, 2015). It is also well documented that membrane fusion, crucial for exocytosis, may be promoted by distending the vesicle membrane (a physical factor raising the surface free energy of the granule membrane, favoring fusion) (Ornbern et al., 1995; Kelly et al., 2004; Jeremic et al., 2005; Mellander et al., 2014).

Despite the fact that it is well documented that secretory granules, in activated platelets, are swollen and connected with the channels of OCS (Escolar \& White, 1991; White \& Escolar, 1991; White, 1999), the contribution of granule swelling to platelet secretion is currently poorly recognized (Golembiewska \& Poole, 2015). Here, we hypothesize that continuous water uptake by platelet secretory granules generates force (hydrostatic pressure) which supports not only their inflation, necessary for fusion, but also determines continuous one-way cargo movement from granules to the OCS channels/ plasma membrane and further, to the exterior surface. The role of AQPs in this model is likely to promote a rapid influx of water into secretory granules. In line with this idea is our finding that the platelet dense and alpha granules are rich in AQPs (Fig. 1C-D), and that thrombin- or monensin-evoked changes in the intracellular AQPs distribution (dispersing of AQP-related signals visible under confocal microscope, reflecting granule swelling, (Fig. 1F)) were almost completely reduced following treatment of platelets with $100 \mu \mathrm{M}$ of $\mathrm{Au}(\mathrm{III})$, a concentration of AQP blocker completely reducing platelet secretion from the dense and alpha granules induced by physiological stimulators and monensin (Fig 2A-B). Accordingly, Au(III) also reduces secretion from the dense granules induced by calcium ionophore A23187 (Fig. 8). Experiments performed on isolated platelet granules have revealed that calcium ions trigger secretory vesicle swelling (van der Meulen \& Grinstein, 1982; van der Meulen \& Grinstein, 1983).

Therefore, it is likely that in platelets AQPs play a role in secretion through the regulation of the vesicle volume. In this context it is of importance to note that the role of AQPs in the swelling of secretory granules was previously demonstrated in chromaffin cells, neurons, and exocrine pancreas cells (Jeremic et al., 2005; Sugiya \& Matsuki, 2006; Ohta et al., 2009; Ishibashi et al., 2014). Substantial similarity between platelet and chromaffin cell secretory systems has been recognized (Fitch-Tewfik \& Flaumenhaft, 2013).

Our results are consistent with the previous report showing that platelets from children with a mutation of AQP7 have impaired ATP secretion from dense granules (Goubau et al., 2013). In the very recently published paper, Agbani et al. demonstrated that platelets from AQP1 knockout mice have only slightly impaired secretion from the dense granules (Agbani et al., 2018). This was interpreted to mean that AQP1 is not directly involved in the platelet secretory response. In the same report, the authors demonstrated that in platelets from wild type mice AQP1 is localized in the membranes of OCS but not in the granule membranes. However, it is highly likely that other types of AQPs may be involved in platelet secretion, especially those which we found to be present in the dense bodies and alpha granules, and those previously reported to play a role in secretion in platelets and other cells i.e. AQP5 (Sugiya et al., 2008), AQP6 (Jeremic et al., 2005), AQP7 (Goubau et al., 2013), and AQP12 (Ohta et al., 2009).

The results presented here indicate a minor role for AQPs in the platelet aggregatory process (Fig. 8). As reported here, the $\mathrm{Au}(\mathrm{III})$-related inhibition of aggregation induced by epinephrine resulted most likely from impaired secretion rather than from any direct effect on aggregation. This is based on observation that in platelets stimulated by adrenaline, the second wave of aggregation starts simultaneously with secretion. Interestingly, Au(III) did not reduce platelet aggregation evoked by arachidonic acid and PMA (PKC activator), and only slightly inhibited aggregation induced by calcium ionophore A23187, indicating that $\mathrm{Au}(\mathrm{III})$ did not affect the platelet responses through the reduction of thromboxane $A_{2}$ formation, modulation of the PKC pathway or deregulation of calcium signaling.

The important finding of this study is identification of $\mathrm{HAuCl}_{4}(10-100 \mu \mathrm{M})$ as a new potent and specific inhibitor of platelet secretion. Of importance, $100 \mu \mathrm{M}$ $\mathrm{Au}(\mathrm{III})$ is able to completely block platelet secretion without reducing their aggregation (Fig. 8).

The limitation of this study is the fact that it is not certain whether $\mathrm{HAuCl}_{4}$ equally blocks all of the AQPs channels. It is also difficult to specify which subtypes of AQPs play a role in secretion. Further studies with AQP knockout models are required to completely resolve these questions. The limitations of this study also comprise imaging of APQs with polyclonal antibodies. The presence of these AQP isoforms should be confirmed in the future by more sensitive detection systems (i.e. monoclonal antibodies, proteomics-related techniques).

In conclusion, this study has revealed that human platelets contain numerous subtypes of AQPs water channels localized both, in the plasma and granule membranes. Rapid water transport through AQPs localized in platelet plasma membrane may be vital for adaptation of these cells to sudden changes in plasma osmolality. AQPs localized in secretory granules play a role in their rapid swelling which seems to be crucial for the release of their cargo. $\mathrm{HAuCl}_{4}$ is emerging as a specific and potent blocker of platelet secretion and a novel tool for examination of the contribution of platelet secretory process to hemostasis. Our finding that blocking of the aquaporin water channels results in complete inhibition of the platelet secretion induced by all physiological stimulators (including activator of thrombin receptor) is of great clinical importance. None of the currently used antiplatelet drug are able to inhibit platelet secretion induced by the strongest platelet stimulus, i.e. thrombin. At pathological conditions, large quantities of thrombin can be produced following sudden rupture of atherosclerotic plaque (Badimon \& Vilahur, 2014). Recently published studies strongly indicate that platelet secretion is critical for the thrombus growth (Golembiewska \& Poole, 2015; de Witt et al., 2014; Konopatskaya et al., 2009). Our findings thus create basis for projection of new generation of the antiplatelet drugs.

\section{Conflict of Interest Statements}

All authors declare no competing financial interests. 


\section{Authorship Contributions}

M.T. and T.M. designed research, performed experiments, analyzed the data, and wrote the manuscript. T.R., J.B.-J., M.G, and A.G. performed experiments and analyzed the data. B.S. performed electron microscopic examination of platelet ultrastructure. M.B. contributed to the acquisition of data. M.T. and T.M. contributed equally to this work. All authors reviewed and edited the manuscript, and approved its final version.

\section{Acknowledgments}

We would like to thank Izabela Prokop for her great support with imaging of Western Blots.

\section{Acknowledgments of Financial Support}

This study was supported by research funding from the Medical University of Bialystok (grant no. 12401957 F) and National Science Centre, Poland (grant no.2017/01/X/NZ3/00338). This study was conducted with the use of equipment purchased by the Medical University of Bialystok as part of the OPDEP 20072013, Priority Axis I.3, contract No POPW.01.03.00-20$022 / 09$

\section{REFERENCES}

Agbani EO, Williams CM, Li Y, van den Bosch MT, Moore SF, Mauroux A, Hodgson L, Verkman AS, Hers I, Poole AW (2018) Aquaporin-1 regulates platelet procoagulant membrane dynamics and in vivo thrombosis. JCI Insight 3(10): pii: 99062. https://doi.org/ 10.1172/jci.insight.99062. [Epub ahead of print]

Agre, P, King LS, Yasui M, Guggino WB, Ottersen OP, Fujiyoshi Y, Engel A, Nielsen S (2002) Aquaporin water channels - from atomic structure to clinical medicine. I Physiol 542: 3-16. https://doi. org/10.1113/jphysiol.2002.020818

Badimon L, Vilahur G (2014) Thrombosis formation on atherosclerotic lesions and plaque rupture. I Intern Med 276: 618-632. https://doi. org/10.1111/joim.12296

Barnard PJ, Berners-Price SJ (2007) Targeting the mitochondrial cell death pathway with gold compounds. Coord Chem Rev 251: 18891902. https://doi.org/10.1016/j.ccr.2007.04.006

Benga G (2012) On the definition, nomenclature and classification of water channel proteins (aquaporins and relatives). Mol Aspects Med 33: 514-517. https://doi.org/10.1016/j.mam.2012.04.003

Born GV, Cross MJ (1963) The aggregation of blood platelets. J Physiol 168: 178-195

CarbreyJM, Agre P (2009) Discovery of the aquaporins and development of the field. Handb Exp Pharmacol 190: 3-28. https://doi. org/10.1007/978-3-540-79885-9_1

Cho SJ, Sattar AK, Jeong EH, Satchi M, Cho JA, Dash S, Mayes MS, Stromer MH, Jena BP (2002) Aquaporin 1 regulates GTP-induced rapid gating of water in secretory vesicles. Proc Natl AcadSci USA 99: 4720-4724. https://doi.org/10.1073/pnas.072083499

de Almeida A, Mósca AF, Wragg D, Wenzel M, Kavanagh P, Barone G, Leoni S, Soveral G, Casini A (2017) The mechanism of aquaporin inhibition by gold compounds elucidated by biophysical and computational methods. Chem Commun (Camb) 53: 3830-3833. https://doi.org/10.1039/c7cc00318h

de Witt SM, Verdoold R, Cosemans JM, Heemskerk JW (2015) Insights into platelet-based control of coagulation. Thromb Res 133: S139-S148. https://doi.org/10.1016/S0049-3848(14)50024-2

Escolar G, White JG (1991) The platelet open canalicular system: a final common pathway. Blood Cells 17: 467-495

Esteva-Font C, Jin BJ, Lee S, Phuan PW, Anderson MO, Verkman AS (2016) Experimental evaluation of proposed small-molecule inhibitors of water channel aquaporin-1. Mol Pharmacol 89: 686-693. https://doi.org/10.1124/mol.116.103929

Eyer P, Worek F,KiderlenD,SinkoG,Stuglin A, Simeon-Rudolf V Reiner E (2003) Molar absorption coefficients for the reducedEllmanreagent: reassessment. Anal Biochem 312: 224-227. https://doi. org/10.1016/S0003-2697(02)00506-7

Fang Q, Lindau M (2014) How could SNARE proteins open a fusion pore? Physiology (Bethesda) 29: 278-285. https:/doi.org/10.1152/ physiol.00026.2013

Fitch-Tewfik JL, Flaumenhaft R (2013) Platelet granule exocytosis: a comparison with chromaffin cells. Front Endocrinol (Lausanne) 4: 1-11. https://doi.org/10.3389/fendo.2013.00077
Geisow MJ, Burgoyne RD (1982) Effect of monensin on chromaffin cells and the mechanism of organelle swelling. Cell Biol Int 6: 933939. https://doi.org/10.1016/0309-1651(82)90004-2

Golebiewska EM, Poole AW (2015) Platelet secretion: From haemostasis to wound healing and beyond. Blood Rev 29: 153-162. https:// doi.org/10.1016/j.blre.2014.10.003

Goubau C, Jaeken J, Levtchenko EN, Thys C, Di Michele M, Martens GA, Gerlo E, De Vos R, Buyse GM, Goemans N, Van Geet C,Freson K (2013) Homozygosity for aquaporin 7 G264V in three unrelated children with hyperglyceroluria and a mild platelet secretion defect. Genet Med 15: 55-63. https://doi.org/10.1038/gim.2012.90

Grinstein S, van der Meulen J, Furuya W (1982) Possible role of $\mathrm{H}^{+}$-alkali cation countertransport in secretary granule swelling during exocytosis. FEBS Lett 148: 1-4. https://doi.org/10.1016/00145793(82)81230-1

Gutmann I, Wahlefeld AW (1985) L-(+) Lactate determination with lactate dehydrogenase and NAD In Methods of Enzymatic Analysis. Bergmeyer HU ed, 1464-1468. VCH VelagsgesellschaftmbH, Weiheim

Hub JS, de Groot BL (2008) Mechanism of selectivity in aquaporins and aquaglyceroporins. Proc Natl Acad Sci U S A 105: 1198-1203. https://doi.org/10.1073/pnas.0707662104

Ishibashi K (2006) Aquaporin superfamily with unusual npa boxes: S-aquaporins (superfamily, sip-like and subcellular-aquaporins). Cell MolBiol 52: 20-27. https://doi.org/10.1016/j.bbamem.2006.02.024

Ishibashi K, Kondo S, Hara S, Morishita Y (2011) The evolutionary aspects of aquaporin family. Am J PhysiolRegul Integr Comp Physiol 300: 566-576. https://doi.org/10.1007/978-94-024-1057-0_2

Ishibashi K, Tanaka Y, Morishita Y (2014) The role of mammalian superaquaporins inside the cell. Biochim Biophys Acta 1840: 1507-1512. https://doi.org/10.1016/j.bbagen.2013.10.039

Jeremic A, Cho WJ, Jena BP (2005) Involvement of water channels in synaptic vesicle swelling. Exp Biol Med 230: 674-680. https://doi.org/10.1177/153537020523000910

Kato M, Pisliakov AV, Warshel A (2006) The barrier for proton transport in aquaporins as a challenge for electrostatic models: the role of protein relaxation in mutational calculations. Proteins 64: 829-844. https://doi.org/10.1002/prot.21012

Kelly ML, Cho WJ, Jeremic A, Abu-Hamdah R, Jena BP (2004) Vesicle swelling regulates content expulsion during secretion. Cell Biol Int 28: 709-716. https://doi.org/10.1016/j.cellbi.2004.07.005

Khalili-Araghi F, Gumbart J, Wen PC, Sotomayor M, TajkhorshidE,Schulten K (2009) Molecular dynamics simulations of membrane channels and transporters. Curr Opin Struct Biol 19: 128-137. https:// doi.org/10.1016/j.sbi.2009.02.011

Koncz C, DaugirdasJT (1994) Use of MQAE for measurement of intracellular [Cl-] in cultured aortic smooth muscle cells. Am J Physiol 267: 2114 -2123. https://doi.org/10.1152/ajpheart.1994.267.6.H2114

Konopatskaya O, Gilio K, Harper MT, Zhao Y, Cosemans JM, Karim ZA, Whiteheart SW, Molkentin JD, Verkade P, Watson SP, Heemskerk JW, Poole AW (2009) PKCalpha regulates platelet granule secretion and thrombus formation in mice. I Clin Invest 119: 399-407. https://doi.org/10.1172/JCI34665

Konopatskaya O, Matthews SA, Harper MT, Gilio K, Cosemans JM, Williams CM, Navarro MN, Carter DA, Heemskerk JWM, Leitges M, Cantrell D, Poole AW (2011) Protein kinase C mediates platelet secretion and thrombus formation through protein kinase D2. Blood 118: 416-424. https://doi.org/10.1182/blood-2010-10-312199

Lemons PP, Chen D, Bernstein AM, Bennett MK, Whiteheart SW (1997) Regulated secretion in platelets: identification of elements of the platelet exocytosis machinery. Blood 90: 1490-1500

Mackie IJ, Jones R, Machin SJ (1984) Platelet impedance aggregation in whole blood and its inhibition by antiplatelet drugs. I ClinPathol 37: $874-878$

Madeira A, de Almeida A, de Graaf C, Camps M, Zorzano A, Moura TF, Casini A, Soveral G (2014) A gold coordination compound as a chemical probe to unravel aquaporin-7 function. Chem Bio Chem 15: $1487-1494$

Martins AP, Marrone A, Ciancetta A, Galán Cobo A, Echevarría M, Moura TF, Casini A, Soveral G (May 18, 2012) Targeting aquaporin function: potent inhibition of aquaglyceroporin-3 by a goldbased compound. PLOS ONE. https://dio.org/10.1371/journal. pone.0037435

Mellander LJ, Kurczy ME, Najafinobar N, Dunevall J, Ewing AG, Cans AS (2014) Two modes of exocytosis in an artificial cell. Sci Rep. https://doi.org/doi:10.1038/srep03847

Metcalfe C, Ramasubramoni A, Pula G, Harper MT, Mundell SJ, Coxon $\mathrm{CH}$ (2016) Thioredoxin inhibitors attenuate platelet function and thrombus formation. PLOS ONE 11: e0163006. https://doi. org/10.1371/journal.pone.0163006

Misztal T, Przesław K, Rusak T, Tomasiak M (2013) Peroxynitrite altered platelet mitochondria - a new link between inflammation and hemostasis. Thromb Res 131: e17-e25. https://doi.org/10.1016/j. thromres.2012.11.010

Misztal T, Rusak T, Brańska-Januszewska J, Ostrowska H, Tomasiak M (2015) Peroxynitrite may affect fibrinolysis via the reduction of 
platelet-related fibrinolysis resistance and alteration of clot structure. Free Radic Biol Med 89: 533-547. https://doi.org/10.1016/j.freeradbiomed.2015.09.006

Misztal T, Rusak T, Tomasiak M (2014) Clinically relevant HOCl concentrations reduce clot retraction rate via the inhibition of energy production in platelet mitochondria. Free Radic Res 48: 1443-1453. https://doi.org/10.3109/10715762.2014.960866

Misztal T, Rusak T, Tomasiak M (2014) Peroxynitrite may affect clot retraction in human blood through the inhibition of platelet mitochondrial energy production. Thromb Res 133: 402-411. https://doi. org/10.1016/j.thromres.2013.12.016

Nakagawa S,Kumin S, Fox D,Nitowsky HM (1978) Human hexosaminidase isozymes. III. Distribution and activity of isozymes in peripheral blood leukocytes and platelets. J Lab Clin Med 91: 922-928

Niemietz CM, Tyerman SD (2002) New potent inhibitors of aquaporins: silver and gold compounds inhibit aquaporins of plant and human origin. FEBS Lett 531: 443-447. https://doi.org/10.1016/ S0014-5793(02)03581-0

Ohta E, Itoh T, Nemoto T, Kumagai J, Ko SB, Ishibashi K, Ohno M, Uchida K, Ohta A, Sohara E, Uchida S, Sasaki S, Rai T (2009) Pancreas-specific aquaporin 12 null mice showed increased susceptibility to caerulein-induced acute pancreatitis. Am J Physiol Cell Physiol 297: 1368-1378. https://doi.org/10.1152/ajpcell.00117.2009

Ollivier V, Syvannarath V, Gros A, Butt A, Loyau S, Jandrot-Perrus M, Ho-Tin-Noe B (2014) Collagen can selectively trigger a platelet secretory phenotype via glycoprotein VI. PLOS ONE. https://doi. org/10.1371/journal.pone.0104712

Ornberg RL, Furuya S, Goping G, Kuijpers GA (1995) Granule swelling in stimulated bovine adrenal chromaffin cells: regulation by internal granule $\mathrm{pH}$. Cell Tissue Res 279: 85-92. https://doi. org/10.1007/BF00300694

Papadopoulos MC, Saadoun S, Verkman AS (2008) Aquaporins and cell migration. Pflügers Arch 456: 693-700. https://doi.org/10.1007/ s00424-007-0357-5

Peng H, Kang N, Xu J, Stanton PK, Kang, J (2013) Two distinct modes of exocytotic fusion pore expansion in large astrocytic vesicles. J Biol Chem 288: 16872-16881. https://doi.org/10.1074/jbc. M113.468231

Rosskopf D, Morgenstern E, Scholz W, Osswald U, Siffert W (1991) Rapid determination of the elevated $\mathrm{Na}^{+} / \mathrm{H}^{+}$exchange in platelets of patients with essential hypertension using an optical swelling assay. J Hypertens 9: 231-238

Saadoun S, Papadopoulos MC, Hara-Chikuma M, Verkman AS (2005) Impairment of angiogenesis and cell migration by targeted aquaporin-1 gene disruption. Nature 434: 786-792. https://doi. org $/ 10.1038 /$ nature 03460

Schwab A, Fabian A, Hanley PJ, Stock C (2012) Role of ion channels and transporters in cell migration. Physiol Rev 92: 1865-1913. https://doi.org/10.1152/physrev.00018.2011

Siffert W, Siffert G, Scheid P, Akkerman JW (1989) Activation of $\mathrm{Na}^{+} / \mathrm{H}^{+}$exchange and $\mathrm{Ca}^{2+}$ mobilization start simultaneously in thrombin-stimulated platelets. Evidence that platelet shape change disturbs early rises of BCECF fluorescence which causes an under- estimation of actual cytosolic alkalinization. Biochem J 258: 521-527. https://doi.org/10.1042/bj2580521

Stafford MJ, Watson SP, Pears CJ (2003) PKD: a new protein kinase C-dependent pathway in platelets. Blood 101: 1392-1399. https:// doi.org/10.1182/blood-2002-08-2384

Strober W (2015) Trypan blue exclusion test of cell viability. Curr Protoc Immunol 111: A3.B.1-3. https://doi.org/10.1002/0471142735. ima03bs 21

Sudhof TC, Rothman JE (2009) Membrane fusion: grappling with SNARE and SM proteins. Science 323: 474-477. https://doi.org/ $10.1126 /$ science. 1161748

Sugiya H, Matsuki M (2006) AQPs and control of vesicle volume in secretory cells. J Membr Biol 210: 155-159. https://doi.org/10.1007/ s00232-005-0853-5

Sugiya H, Matsuki M, Hashimoto S (2008) Role of aquaporins and regulation of secretory vesicle volume in cell secretion. J Cell Med 12: 1486-1494. https://doi.org/10.1111/j.1582-4934.2008.00239.x

Sui H, Han BG, Lee JK, Walian P, Jap BK (2001) Structural basis of water-specific transport through the AQP1 water channel. Nature 414: 872-878. https://doi.org/10.1038/414872a

Suwalsky M, Zambenedetti P, Carpene E, Ibn-Lkayat M, Wittkowski W, Messori L, Zatta P (2004) Effects of chronic treatment with sodium tetrachloroaurate(III) in mice and membrane models. I Inorg Biochem 98: 2080-2086. https://doi.org/10.1016/j.jinorgbio. 2004.09 .015

Tomasiak M, Stelmach H, Rusak T, Wysocka J (2004) Nitric oxide and platelet energy metabolism. Acta Biochim Pol 51: 789-803. https:// doi.org/045103789

Van der Meulen J, Grinstein S (1982) $\mathrm{Ca}^{2+}$-induced lysis of platelet secretory granules. J Biol Chem 257: 5190-5195

Van der Meulen, J, Grinstein S (1983) Studies on the $\mathrm{Ca}^{2+}$-induced lysis of platelet alpha-granules. Arch Biochem Biophys 224: 117-126

Verkman AS, Anderson MO, Papadopoulos MC (2014) Aquaporins: important but elusive drug targets. Nat Rev Drug Discov 13: 259-277. https://doi.org/10.1038/nrd4226

Verkman AS (2012) Aquaporins in clinical medicine. Annu Rev Med 63: 303-316. https://doi.org/10.1146/annurev-med-043010-193843

Verkman AS (2014) More than just water channels: unexpected cellular roles of aquaporins. J Cell Sci 118: 3225-3232. https://doi. org/10.1242/jcs.02519

Walz T, Fujiyoshi Y, Engel A (2009) The AQP structure and functional implications. Handb Exp Pharmacol 190: 31-56. https://doi. org/10.1007/978-3-540-79885-9_2

White JG (1999) Platelet secretory process. Blood 93: 2422-2425

White JG, Escolar G (1991) The blood platelet open canalicular system: A two way street. Eur J Cell Biol 56: 233-242

Yang B, Kim JK, Verkman AS (2006) Comparative efficacy of $\mathrm{HgCl} 2$ with candidate aquaporin-1 inhibitors DMSO, gold, TEA ${ }^{+}$and acetazolamide. FEBS Lett 580: 6679-6684. https://doi.org/ 10.1016/j. febslet.2006.11.025

Zou T, Lum CT, Lok CN, Zhang JJ, Che CM (2015) Chemical biology of anticancer gold(III) and gold(I) complexes. Chem Soc Rev 44: 8786-8801. https://doi.org/10.1039/c5cs00132c 